\title{
ALFABETIZAÇÃO MATEMÁTICA, LETRAMENTOS E NUMERAMENTO: discussões na formação continuada do PNAIC
}

\author{
Antonio Mauricio Medeiros ALVES ${ }^{1}$
}

\begin{abstract}
Resumo
O Pacto Nacional pela Alfabetização na Idade Certa - PNAIC é um programa de formação continuada de professores alfabetizadores, financiado pelo governo federal brasileiro, com o principal objetivo de garantir a alfabetização de todas as crianças dos 6 aos 8 anos de idade, matriculadas nas escolas públicas. Para tanto, desde 2013, as universidades brasileiras, tanto da rede pública quanto privada, têm se dedicado à oferta de cursos promovidos por esse programa, versando sobre a alfabetização em suas múltiplas facetas. No ano de 2014, o foco das formações foi o ensino de Matemática nos anos iniciais, tendo como pano de fundo das discussões a Alfabetização Matemática das crianças matriculadas no ciclo de alfabetização (6 aos 8 anos), bem como conceitos como letramento matemático e numeramento. Esse texto problematiza essa formação dos professores alfabetizadores a partir da discussão sobre esses conceitos e as práticas de formação desenvolvidas pela Universidade Federal de Pelotas, no ano de 2014.
\end{abstract}

Palavras-chave: PNAIC. Alfabetização Matemática. Formação continuada. Anos Iniciais.

\footnotetext{
${ }^{1}$ Licenciatura Plena em Matemática pela Universidade Católica de Pelotas (1996) e Graduação em Pedagogia pelo Centro Universitário Internacional - UNINTER (2018). Especialização em Educação Matemática (1997), pela mesma universidade, Mestrado (2005) e Doutorado (2013) em Educação pela Universidade Federal de Pelotas.

E-mail: alves.antoniomauricio@gmail.com
} 


\title{
MATHEMATICAL LITERACY, LITERACY AND NUMERACY: discussions of PNAIC's continuing education
}

\author{
Antonio Mauricio Medeiros ALVES
}

\begin{abstract}
The National Pact for Literacy at the Right Age - PNAIC is a continuing education program for literacy teachers, which is funded by the Brazilian federal government and whose main objective is to guarantee literacy for all children 6 to 8 years old enrolled in public schools. For that end, since 2013 Brazilian universities have been offering courses, promoted by this program, which approach literacy from its many facets. In 2014 there was a focusing on the training for the teaching of Mathematics in the early school years, which had as a background the discussions of Mathematical Literacy of children enrolled in the literacy cycle (6 to 8 years old), as well as concepts such as Mathematical Literacy and Numeracy. This text problematizes the formation of literacy teachers, starting from a discussion of this concept and of the formation practices developed by the Federal University of Pelotas in 2014.
\end{abstract}

Keywords: PNAIC. Mathematical Literacy. Continuing Education. Early Years. 


\section{Introdução}

Este texto tem por objetivo problematizar a formação continuada de alfabetizadores, a partir da proposta do Pacto Nacional pela Alfabetização na Idade Certa (PNAIC), cujo objetivo para o ano de 2014 foi a formação Matemática dos professores do ciclo de alfabetização, ${ }^{2}$ centrada principalmente no conceito de Alfabetização Matemática.

Para tanto, é necessário, inicialmente, discutir a importância e o papel da Alfabetização Matemática no processo de ensino dessa matéria nos anos iniciais do Ensino Fundamental, bem como sobre questões que envolvem os diferentes letramentos, dentre eles o letramento matemático e, ainda, o numeramento. Também é fundamental uma problematização sobre a criança e a Matemática, sobre o desenvolvimento cognitivo e o aprendizado e sobre teorias da aprendizagem, na perspectiva do ensino de Matemática nos anos iniciais. Da mesma forma cabe uma reflexão sobre a formação do pedagogo que, apesar de não ter habilitação específica na área de matemática, visto que a titulação exigida para atuação nos anos iniciais é a Pedagogia e a Matemática não habilita o licenciado para docência nesse nível de ensino, ainda assim, é um professor que ensina Matemática (PEM).

O ensino de Matemática tem sido tema de muitas discussões ao longo dos tempos, tanto no Brasil quanto no mundo. Nessas discussões, as palavras sucesso e fracasso parecem estar sempre presentes, em todos os níveis: da educação básica ao ensino superior.

Em toda discussão que dura muito tempo, é normal o surgimento daquilo que chamamos de "lugar-comum", ou seja, aquele argumento ou ideia bem conhecida, trivial. Quando tratamos dos baixos índices de rendimento no ensino de Matemática, o lugarcomum que sempre se apresenta é que faltam pré-requisitos aos estudantes. Ou seja, se meu aluno não aprende, o problema não está em minha prática docente, mas sim no próprio aluno que não apresenta o necessário conhecimento matemático anterior para o desenvolvimento de novos conceitos.

Assim, a responsabilidade é lançada para o nível de ensino imediatamente anterior: do Ensino Superior para o Ensino Médio, deste para os Anos Finais do Ensino Fundamental e, finalmente, destes para os Anos Iniciais da escolarização.

Mesmo não concordando com esse pensamento - simplista em uma primeira análise, porém recorrente nos discursos - este texto traz algumas reflexões sobre o papel da Alfabetização Matemática no Pacto Nacional pela Alfabetização na Idade Certa (PNAIC) para a formação dos professores.

2 O ciclo de alfabetização compreende os três primeiros anos do Ensino Fundamental (BRASIL, 2010). 


\title{
O Pacto Nacional pela Alfabetização na Idade Certa (PNAIC)
}

Desde o ano de 2010, a Resolução ${ }^{\circ}$ 7, de 14 de dezembro, fixa as Diretrizes Curriculares Nacionais do Ensino Fundamental de Nove Anos, definindo, em seu Artigo 49, que:

o Ministério da Educação, em articulação com os Estados, os Municípios e o Distrito Federal, deverá encaminhar ao Conselho Nacional de Educação, precedida de consulta pública nacional, proposta de expectativas de aprendizagem dos conhecimentos escolares que devem ser atingidos pelos alunos em diferentes estágios do Ensino Fundamental. (BRASIL, 2010, p. 14)

Dessa forma, atendendo ao disposto na referida Resolução, o MEC deu início a esta tarefa pela definição dos “Direitos de Aprendizagem” para o Ciclo inicial de $1^{\circ}$ ao $3^{\circ}$ ano do Ensino Fundamental, que passou a ser denominado por Ciclo de Alfabetização. Esses direitos refletem as expectativas a serem atingidas pelos estudantes em cada um dos componentes curriculares.

Assim, em novembro de 2012, o Conselho Nacional de Educação lançou, juntamente com o Pacto Nacional pela Alfabetização na Idade Certa (PNAIC), o documento intitulado "Elementos conceituais e metodológicos para definição dos Direitos de Aprendizagem e Desenvolvimento do Ciclo de Alfabetização ( $1^{\circ}, 2^{\circ}$ E $3^{\circ}$ ANOS) do ensino fundamental”.

Sobre o PNAIC, o referido documento dispõe que o

\begin{abstract}
Pacto Nacional supõe ações governamentais de cursos sistemáticos de Formação de professores alfabetizadores, oferecidos pelas Universidades Públicas participantes da Rede de Formação, a disponibilização de materiais pedagógicos fornecidos pelo MEC, assim como um amplo sistema de avaliações prevendo registros e análise de resultados que induzem ao atendimento mais eficaz aos alunos em seu percurso de aprendizagem. As ações do Pacto Nacional pressupõem também gestão do processo, controle social e mobilização cujas responsabilidades estão repartidas entre os municípios, os estados e a união. (BRASIL, 2012, p.07)
\end{abstract}

Ou seja, institui-se, por meio do PNAIC, um amplo programa de formação continuada dos professores que atuam nos três primeiros anos do ensino fundamental, sendo destacada a importância e o compromisso das diferentes áreas que compõem o currículo.

Como já mencionado, no ano de 2014, o PNAIC propôs um processo de formação continuada relativo aos conhecimentos matemáticos para os alfabetizadores, entre outros fatores, pela fragilidade do ensino de matemática oferecido nos cursos de formação inicial dos professores que atuarão nos anos iniciais, a qual se dá, majoritariamente - e por força de lei -, nos cursos de Pedagogia.

Essa fragilidade é também destacada pelos Parâmetros Curriculares Nacionais (PCN), ao se referirem ao ensino de Matemática nos anos iniciais:

Parte dos problemas referentes ao ensino de Matemática está relacionada ao processo de formação do magistério, tanto em relação à 
formação inicial como à formação continuada. Decorrentes dos problemas da formação de professores, as práticas na sala de aula tomam por base os livros didáticos, que, infelizmente, são muitas vezes de qualidade insatisfatória. A implantação de propostas inovadoras, por sua vez, esbarra na falta de uma formação profissional qualificada, na existência de concepções pedagógicas inadequadas e, ainda, nas restrições ligadas às condições de trabalho. (BRASIL, 1997, p. 24)

Dessa forma, torna-se importante considerar que os professores tenham uma formação continuada que lhes possibilite desenvolver conhecimentos matemáticos sólidos e eficazes, capazes de garantir aprendizagens significativas. Assim, os saberes do professor dos anos iniciais sobre os objetos de ensino devem abranger os conceitos das áreas de ensino estabelecidos para a escolaridade em que ele atuará, tanto no que se refere à profundidade desses conceitos e sua historicidade como na sua articulação com outros conhecimentos e no seu tratamento didático.

Segundo Curi (2005, p. 157), “é necessário que a formação do professor polivalente desenvolva ou aprimore capacidades como resolver problemas, argumentar, estimar, raciocinar matematicamente, comunicar-se matematicamente”. Para essa autora, desenvolver atitudes positivas em relação à Matemática e ao seu ensino é essencial. O que pressupõe: ter predisposição para usar os conhecimentos matemáticos como recursos para interpretar, analisar e resolver problemas; ter perseverança na busca de resultados; ter interesse em utilizar diversas representações Matemáticas e; ter confiança em si mesmo para aprender e ensinar Matemática.

Curi (2005) também destaca que grande parte dos cursos superiores de formação de professores para os anos iniciais (Pedagogia e Normal Superior) tem investido na oferta de disciplinas voltadas à formação Matemática desses sujeitos, com ênfase nas questões metodológicas. Entretanto, tais disciplinas têm uma carga horária muito reduzida, mostrando-se, assim, ineficazes ao que se propõem. Dessa forma, diferentes concepções sobre o ensino de Matemática vão se formando entre esses educadores, em decorrência não somente de sua formação inicial, mas, também, dos modelos de professores com quem conviveram ao longo de sua trajetória escolar.

Nacarato, Mengali e Passos (2014, p.23) indicam que seria natural afirmar que, no momento atual, os futuros professores, pessoas entre 20 e 25 anos de idade, "foram expostas a novas práticas de ensino de Matemática”, pois sua trajetória, na escola básica, deu-se em um período de reformas curriculares, entretanto os formadores de professores sabem que isso não é real. Segundo as autoras, além de a formação Matemática destes estudantes estar longe das atuais tendências curriculares, elas trazem, em suas experiências escolares, marcas profundas que lhes causam sentimentos negativos em relação à Matemática, o que muitas vezes implica bloqueios à sua futura prática de ensinar os conteúdos dessa área a seus alunos. 
Esse quadro apresentado pelas autoras era evidenciado nas falas das professoras que declaravam já terem razoável domínio das práticas de alfabetização das crianças, porém percebiam uma grande fragilidade nas ações pedagógicas envolvendo conceitos matemáticos. Condição que elas atribuíam à sua formação inicial, afirmando a necessidade de uma formação continuada que abordasse elementos conceituais e didáticos sobre o ensino de Matemática para as crianças do ciclo de alfabetização (NACARATO, MENGALI, PASSOS, 2014).

O documento "Elementos conceituais e metodológicos para definição dos Direitos de Aprendizagem e Desenvolvimento do Ciclo de Alfabetização (1 ${ }^{\circ}, 2^{\circ}$ E $3^{\circ}$ ANOS) do ensino fundamental” ainda destaca que “o ensino fundamental obrigatório, com duração de 9 (nove) anos, gratuito na escola pública, iniciando-se aos 6 (seis) anos de idade, terá por objetivo a formação básica do cidadão, mediante: (1) o desenvolvimento da capacidade de aprender, tendo como meios básicos o pleno domínio da leitura, da escrita e do cálculo” (BRASIL, 2012, p.22), destacando a importância da Matemática (cálculo) junto ao processo de Alfabetização (leitura e escrita).

Apesar de o documento, à primeira vista, parecer limitador em relação ao papel da Matemática, de início apresentando-a reduzida à habilidade de calcular, mais adiante ela recebe especial atenção, caracterizada como “Alfabetização Matemática”:

Os Direitos e Objetivos de Aprendizagem e Desenvolvimento que envolvem o processo de alfabetização Matemática estão atrelados à compreensão dos fenômenos da realidade. Esta compreensão oferece ao sujeito as ferramentas necessárias para que ele possa agir conscientemente sobre a sociedade na qual está inserido. É papel da escola criar as condições necessárias para que o sujeito possa servir-se dessas ferramentas em suas práticas sociais. Assim, o conceito de letramento matemático está diretamente ligado à concepção de Educação Matemática e tem como espinha dorsal a resolução de situações-problema e o desenvolvimento do pensamento lógico. (BRASIL, 2012, p. 60)

Somos então apresentados a três "novos”3 conceitos: Alfabetização Matemática, Numeramento e Letramento Matemático, problematizados a seguir.

\section{A Alfabetização Matemática na literatura}

O PNAIC apresenta, entre os seus objetivos, o desenvolvimento da alfabetização de modo integrado com as demais áreas do conhecimento, dentre as quais a Matemática ocupa um importante papel. Essa aproximação da Matemática às práticas de alfabetização já foi problematizada por diferentes autores, dentre os quais Machado:

Os elementos constituintes dos dois sistemas fundamentais para a representação da realidade - o alfabeto e os números - são apreendidos conjuntamente pelas pessoas em geral, mesmo antes de chegarem à escola, sem distinções rígidas de fronteiras entre disciplinas ou entre aspectos qualitativos e quantitativos da realidade. (MACHADO, 1990, p. 15)

${ }^{3}$ A palavra "novos” escritas entre aspas deve-se ao fato de que esses conceitos, apesar de presentes há um bom tempo na literatura educacional, ainda são desconhecidos por boa parte dos professores. 
A aproximação proposta pelo autor, entre alfabetização e Matemática, exige-nos o esforço de entendermos o termo Alfabetização de forma mais abrangente. Esse termo pode ser entendido em dois sentidos principais: um stricto e outro lato. No primeiro sentido, a “alfabetização seria o processo de apropriação do sistema de escrita alfabético”, porém, em um sentido mais abrangente ou lato, o termo "supõe não somente a aprendizagem do sistema de escrita, mas também, os conhecimentos sobre as práticas, usos e funções da leitura e da escrita, o que implica o trabalho com todas as áreas curriculares e em todo o processo do Ciclo de Alfabetização” (BRASIL, 2014, p.27).

Nesse sentido lato de alfabetização, um "novo" conceito se apresenta: o de Alfabetização Matemática. "Novo” porque é praticamente desconhecido no meio educacional, porém, apesar de ainda pouco debatido, o conceito de alfabetização Matemática tem sido recorrente nos discursos sobre educação, como Ocsana Danyluk, que o apresenta em sua dissertação de mestrado: "refere-se aos atos de aprender a ler e a escrever a linguagem Matemática usada nas primeiras séries da escolarização. Ser alfabetizado em Matemática é entender o que se lê e escrever o que se entende a respeito das primeiras noções de aritmética, de geometria e da lógica” (DANYLUK, 1998, p.14).

O PNAIC traz esse conceito como um dos pilares do ensino de Matemática nos anos iniciais, apresentando-o aos professores alfabetizadores como:

O processo de organização dos saberes que a criança traz de suas vivências anteriores ao ingresso no Ciclo de Alfabetização, de forma a levá-la a construir um corpo de conhecimentos matemáticos articulados, que potencializem sua atuação na vida cidadã. (BRASIL, 2012, p. 60)

Dessa forma, a Matemática adquire uma nova dimensão, entendida na perspectiva do letramento, ou melhor, como Alfabetização Matemática, compreendendo o conjunto das contribuições da Educação Matemática no Ciclo de Alfabetização, de forma que se promova a apropriação, pelos estudantes, de práticas sociais de leitura e escrita de diversos tipos de textos, práticas de leitura e escrita do mundo, não se limitando ao ensino do sistema de numeração e das quatro operações aritméticas fundamentais (BRASIL, 2014, p.31).

Ou seja, amplia-se o conceito de Matemática, que passa a contemplar as diferentes práticas de leitura e escrita desenvolvidas pelas crianças, tanto no contexto escolar quanto fora dele. Considera-se, também, as relações com o espaço e as formas, os processos de medição, registro e uso das medidas, como também as estratégias de produção, reunião, organização, registro, divulgação, leitura e análise de informações, além do tratamento da informação, promovendo a articulação de procedimentos de identificação e isolamento de atributos na resolução de conjuntos, bem como de comparação, classificação e ordenação, operações mentais básicas para o desenvolvimento pleno dos conceitos matemáticos (BRASIL, 2014, p.31). 
A relação entre essas operações mentais e as estruturas Matemáticas não é novidade na literatura educacional, já tendo sido apresentada por Piaget (1979), em seu livro intitulado Estruturalismo, no qual o autor estabelece a correspondência entre as três estruturas-mãe (Bourbaki) e as estruturas do pensamento.

O desenvolvimento dessas estruturas - mesmo sem relação direta com os conceitos matemáticos que se pretendem ensinar como, por exemplo, os números e suas operações, para o caso do Ensino Primário - levaria o aluno à construção desses conceitos. Encontramos em Lima (1980) que, para Piaget, a inteligência é o resultado do processo combinatório das estruturas mentais e suas correspondentes na Matemática, sem perderem sua identidade, ou seja, mesmo associadas, cada uma das estruturas mantém suas propriedades originais

Dessa forma, as estruturas Matemáticas (algébricas, de ordem e topológicas) estariam associadas a estruturas mentais (classificação, seriação e continuidade) (ALVES, 2013, p. 77).

A partir da relação entre tais estruturas, considerada quase uma "revolução conceitual” no que se refere ao ensino de Matemática, decorre a maior preocupação da epistemologia genética que, segundo Piaget e Inhelder, caracteriza-se por:

Compreender porque a organização do comportamento de classificação e de seriação assume esta ou aquela forma, e por que essas formas sucessivas tendem a converter-se em estruturas lógicoMatemáticas (não porque a Lógica ou as Matemáticas tivessem imposto os modelos, a priori, mas porque o sujeito, sem os conhecer, tende por si mesmo a construir formas que lhes são progressivamente isomorfas). (PIAGET, INHELDER, 1975, p. 342)

De acordo com Lima (1980), Piaget indica que uma metodologia para o ensino da Matemática deveria contemplar o desenvolvimento das estruturas mentais (classificação, seriação e continuidade) que, ao contrário do que se imaginou por muito tempo, não são intuitivas (não existem a priori) e nem se constroem pela imposição dos modelos matemáticos, devendo ser construídas, portanto, através de atividades variadas.

Percebe-se, então, que o ensino de Matemática não pode ficar restrito aos números e às operações aritméticas, visto que as demais estruturas Matemáticas e do pensamento devem ser mobilizadas desde os anos iniciais. Assim, a alfabetização Matemática deve ser entendida para além do domínio dos números e de suas operações. Desde o início da escolaridade, a criança deve construir as primeiras noções de espaço, forma e suas representações, bem como devem lhe ser oferecidas as condições para que as ideias iniciais de grandezas, como comprimento e tempo, por exemplo, possam ser organizadas, desde a tenra idade, , pensando na função social da Matemática.

\section{Letramento Matemático ou Numeramento?}

Falar na função social da Matemática leva-nos a uma ampliação da expressão alfabetização Matemática como a encontramos no Caderno de Apresentação de Matemática 
do PNAIC, em referência ao letramento matemático (BRASIL, 2014, p.43).

Entretanto, esse caderno não apresenta um conceito ou mesmo o que se entende pela expressão letramento matemático, sendo necessária a busca, em outras fontes, de uma definição ou conceito que possa contribuir para este debate. Tal como o conceito de letramento que, como nos apresenta Soares (2004), está relacionado às práticas sociais de leitura e escrita, em Moretti e Souza (2015, p. 20) encontramos que a expressão letramento matemático está associada "a processos de uso de conceitos matemáticos em práticas sociais", aproximando-se do conceito de numeramento, termo do campo da educação Matemática, surgido em função das demandas sociais.

Mais recente que o uso do termo letramento, chegado ao Brasil em meados da década de 1980 (SOARES, 2006, p.15), o termo numeramento, conforme Toledo (2004, p.93), foi apresentado à Faculdade de Educação da Universidade de São Paulo em abril de 2003.

O misto de habilidades essenciais, tanto da Matemática como do letramento, caracteriza, então, o conceito de numeramento como:

[...] um agregado de habilidades, conhecimentos, crenças e hábitos da mente, bem como as habilidades de comunicação e resolução de problemas, que os indivíduos precisam para efetivamente manejar as situações do mundo real ou para interpretar elementos matemáticos ou quantificáveis envolvidos em tarefas. (CUMMING, GAL, GINSBURG, 1998, p.2; apud TOLEDO, 2004, p.94, grifo nosso).

A expressão mundo real, grifada na citação acima, não pode ser reduzida ao cotidiano do aluno fora da escola. Muitas vezes, quando falamos em "vida real", queremos nos referir aos acontecimentos extraescolares e nos esquecemos de que a escola também faz parte desse mundo real, estando nela presentes, além de conhecimentos a serem ensinados e aprendidos, jogos e brincadeiras, que fazem parte do mundo infantil.

Moretti e Souza (2015) também destacam a existência de uma vertente da Educação Matemática que relaciona numeramento a uma ideia mais ampla de letramento, incluindo tanto as práticas sociais quanto as condições do sujeito para se inserir socialmente e atender às demandas das práticas perpassadas pela linguagem escrita.

Para as autoras, ao se compreender a noção de letramento de uma forma mais abrangente, o conceito de numeramento assumiria outra dimensão, não mais caracterizado como um letramento matemático, paralelo ao letramento, mas um fenômeno próprio de numeramento como uma dimensão do letramento. Isso implicaria rever a própria visão de escrita, que seria ampliada para além do domínio de códigos alfabéticos, mas abrangendo também os códigos numéricos e simbólicos.

Porém Moretti e Souza (2015) destacam que, apesar de os termos numeramento, alfabetização matemática e letramento matemático já serem recorrentes em diferentes publicações, os autores não têm um consenso sobre esses conceitos, que ora se aproximam ora se afastam, apresentando características próprias segundo o contexto. Entretanto, 
qualquer que seja a compreensão desses conceitos no meio educacional, é fato que o ensino de Matemática para as crianças é, atualmente, considerado de grande importância para o desenvolvimento dos estudantes nessa área, da mesma forma como é consenso que o ensino de Matemática não pode se dar de forma isolada, como destaca o Caderno de Apresentação:

Entender a Alfabetização Matemática na perspectiva do letramento impõe o constante diálogo com outras áreas do conhecimento e, principalmente, com as práticas sociais, sejam elas do mundo da criança, como os jogos e brincadeiras, sejam elas do mundo adulto e de perspectivas diferenciadas, como aquelas das diversas comunidades que formam o campo brasileiro. (BRASIL, 2014, p.15)

Portanto, devemos compreender que a Matemática escolar deve estar conectada às práticas sociais do mundo da criança, fazendo parte de suas vidas, uma vez que as crianças, muitas vezes, passam mais tempo na escola do que fora dela, desenvolvendo, a todo momento, habilidades Matemáticas, em outros espaços além dos limites da sala de aula.

Entende-se por "habilidades Matemáticas" a capacidade de mobilização de conhecimentos associados a quantificação, ordenação, operações, realização de tarefas ou resoluções de problemas relativos à Matemática, tendo sempre como referência as tarefas e situações cotidianas. Assim, lidar com números, compreender tabelas e gráficos, trabalhar com noções de escala, régua e proporção, são exemplos de habilidades que realizamos e que influenciam a nossa compreensão e comunicação.

Reconhecidamente, mesmo antes de sua vida escolar, as crianças:

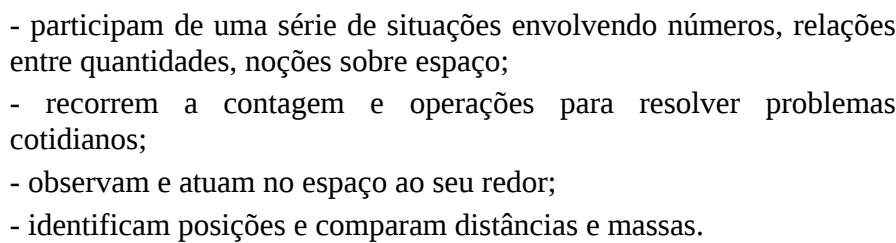

Assim, cabe à escola articular essas experiências extraescolares, assistemáticas (experiências que não são organizadas nem seguem uma sequência didática elaborada) e heterogêneas (cada criança terá desenvolvido diferentes habilidades, de acordo com os estímulos aos quais é exposta) com os conhecimentos matemáticos socialmente construídos, por meio de situações que desafiem os conhecimentos iniciais das crianças, ampliando-os e sistematizando-os, considerando, principalmente, que:

[...] uma vez que a aprendizagem dos conceitos científicos não se dá de maneira espontânea, cabe à escola organizar situações de ensino que coloquem as crianças diante de situações cuja resolução necessite do conceito que se deseja ensinar e, ao mesmo tempo, de forma mediada pelos professores, possibilitem a superação da superficialidade do contexto e da exploração de características essenciais dos conceitos, em direção à abstração. (MORETTI, SOUZA, 2015, p.25)

Com isso, as autoras afirmam que educar pressupõe a mediação entre a cultura e os estudantes, ou seja, educar compreende considerar o conhecimento prévio das crianças. Mas de um modo que os leve à interiorizar, transformar e garantir a continuidade dessa cultura que, nas escolas, torna-se objeto de ensino validado socialmente como conteúdo escolar. 
Retornando à pergunta título desta seção, encontramos em Moretti e Souza (2015), como já mencionado, que: apesar de os termos “alfabetização Matemática”, “numeramento" e "letramento matemático" aparecerem em diferentes documentos e publicações, tanto os seus usos quanto os seus sentidos não são consensuais, mas está presente nos dois últimos, com certeza, uma preocupação com a função social da Matemática.

A fim de que a Matemática exerça sua função social, prevista em todos os documentos oficiais (BRASIL, 2012), deve ser apresentada às crianças a necessidade de organizar e de comunicar informações de maneira eficaz, através do contato com os diversos meios de comunicação, de modo que elas mesmas passem a reconhecer tabelas e gráficos simples, que são elementos facilitadores da compreensão de diferentes informações.

Em vista disso, através da formação proposta pelo PNAIC e desenvolvida pela Universidade Federal de Pelotas - UFPel, em 2014, foram tratados os seguintes temas: Organização do Trabalho Pedagógico; Quantificação, Registros e Agrupamentos; Construção do Sistema de Numeração Decimal; Operações na Resolução de Problemas; Geometria; Grandezas e Medidas; Educação Estatística; Saberes Matemáticos e Outros Campos do Saber.

Além disso, sempre que possível, foram problematizadas as origens de produção dos conceitos matemáticos, uma vez que esse conhecimento, contemplando "as necessidades que o motivaram, as soluções encontradas para responder a essa necessidade, suas contradições e seus impasses” (MORETTI, SOUZA, 2015, p.26), facilita aos professores a proposição de situações de ensino que apresentem às crianças situações semelhantes. $\mathrm{O}$ que, embora não significando reproduzir o contexto histórico, contribuirá para um melhor entendimento dos motivos que levaram à produção daquele conhecimento específico.

A seguir, é discutida a proposta de formação desenvolvida pela UFPel, na qual foram desenvolvidos os temas citados nos parágrafos anteriores.

\section{A formação do PNAIC na UFPel: organização e concepção}

Com a adesão da UFPel ao PNAIC, no ano de 2013, foi constituída uma equipe nessa IES, ${ }^{4}$ responsável pelas formações, sendo redefinida para 2014, quando a temática da formação foi a Alfabetização Matemática. Nesse momento, houve troca da coordenação geral da equipe que, para atender 19 turmas, passou a contar com 02 coordenadores adjuntos, 05 supervisores, em uma equipe mista de formadores com 19 professores da área de linguagem e 13 da área de Matemática e, aproximadamente, 460 orientadores de estudos, que deveriam atender a formação de cerca de 9000 professores alfabetizadores,

\footnotetext{
${ }^{4}$ Instituição de Ensino Superior.
} 
dos quais foram certificados 7804 cursistas (os demais não atingiram o mínimo de frequência ou aproveitamento no curso de formação).

A partir das manifestações de muitos formadores das IES, ainda em 2013, de que não se sentiam capacitados para trabalhar as questões do conhecimento matemático com os orientadores de estudos que, posteriormente, ministrariam a formação aos professores alfabetizadores, o MEC disponibilizou o dobro de vagas de formadores para o ano de 2014, com o objetivo de que a formação fosse ministrada em duplas: um formador da área de linguagem e outro com formação em Matemática. Porém, como a Matemática dos anos iniciais não é, normalmente, trabalhada nos cursos de Licenciatura em Matemática e é pouco desenvolvida nos cursos de Pedagogia, houve uma grande dificuldade na seleção dos formadores de Matemática, ficando com os dois formadores atuando somente em 13 das 19 turmas atendidas pela universidade. As demais 06 turmas tiveram somente o formador de linguagem. Esse fato corrobora a necessidade de mais investimentos em formação continuada na área da Matemática dos anos iniciais, visto a fragilidade dessa formação para grande parte dos professores.

A metodologia empregada nas formações previa encontros em momentos distintos. Inicialmente, a equipe de coordenação e os supervisores reuniam-se a fim de articular as áreas da linguagem e da Matemática, visando subsidiar os formadores através da problematização dos conhecimentos de ambas as áreas. Os formadores, por sua vez, a partir de reuniões quinzenais, realizavam sessões coletivas de estudo, com a leitura prévia, em duplas, dos cadernos de formação ${ }^{5}$ disponibilizados pelo MEC, com posterior discussão no grupo geral de formadores, para a elaboração de estratégias metodológicas.

Eram, ainda, realizados estudos de materiais de apoio indicados pela equipe de supervisores e pela coordenação, a fim de realizar o planejamento, em grupos, da formação a ser ministrada nos três polos, ${ }^{6}$ realizando, em seguida, a socialização das ideias, no grande grupo, para a constituição de uma estrutura de planejamento que estabelecesse uma regularidade na abordagem do fio condutor da formação para os orientadores de estudos (objetivos e temas).

Percebe-se, portanto, que a concepção de formação na UFPel prevê a articulação da pesquisa e formação de professores como oportunidades formativas (WARSCHAUER, 2003) que favorecem a criação e a recriação da ação pedagógica e dos espaços de atuação profissional, o que pressupõe algumas apostas teóricas, dentre as quais a ideia de Canário (1994): de que os indivíduos mudam e, assim, acabam mudando o próprio contexto em que trabalham, sendo fundamental, portanto, que os professores enxerguem-se como sujeitos, mas também como protagonistas do seu processo de formação. Por esse motivo, os relatos de práticas são valorizados nas atividades formativas.

\footnotetext{
${ }^{5}$ Material disponível em http://pacto.mec.gov.br/2012-09-19-19-09-11.

${ }^{6}$ Para atender aos mais de 150 municípios a UFPel dividiu os participantes em três polos: nas cidades de Pelotas, Osório e Porto Alegre, RS.
} 
Por meio desses relatos, foi possível perceber que a formação em contexto produz condições de mudanças; as práticas formativas articulam-se às situações cotidianas de trabalho e aos cotidianos profissionais, organizacionais e comunitários das escolas. Nesse contexto, o acompanhamento dos formadores às práticas dos cursistas foi realizado sempre que possível.

Por isso, diferentes estratégias metodológicas eram adotadas, conforme as características dos polos, entretanto, os encontros de formação contemplavam a realização de estratégias formativas comuns, como: a leitura deleite; o relato de experiências das práticas de formação com os orientadores de estudos; as leituras/atividades de estudo e aprofundamento em grupo; a discussão de textos com sistematização oral e escrita; a atividade de avaliação e de elaboração/análise de diferentes materiais didáticos (recursos pedagógicos para o ensino de Matemática, livros didáticos etc.).

Dentro dessas metodologias, definiu-se o uso de alguns recursos para os encontros de formação, tais como: biografia Matemática e linha do numeramento (atividades de diagnóstico inicial sobre concepções e práticas de alfabetização Matemática e Numeramento); caderneta de metacognição; e o livro da vida, descritos, de modo breve, a seguir.

Objetivando identificar o conhecimento prévio dos cursistas sobre os temas da Alfabetização Matemática a serem trabalhados na formação, citados anteriormente, inicialmente, foi realizado um diagnóstico a partir de duas atividades: biografia Matemática e linha do numeramento.

Num primeiro momento da formação, foi realizada a leitura em grupo sobre os direitos de aprendizagem e os eixos estruturantes da Matemática para os anos iniciais. Após essas leituras, passou-se ao recurso intitulado Biografia Matemática. Essa atividade foi baseada na proposta de Santos (2005), presente no texto "Explorações da Linguagem escrita nas aulas de Matemática”, na categoria nomeada pela autora como pequenos textos.

A Biografia Matemática tem por objetivo, segundo a autora, oferecer ao aluno a oportunidade de se colocar e dar ao professor "pistas" relativas às origens da sua formação de estudante (por exemplo, escola pública ou particular), como também sobre sua disponibilidade de tempo extraclasse, permitindo delinear um breve perfil desse aluno.

São propostas duas questões que envolvem o relato de uma experiência positiva e o de uma negativa com a Matemática, o que ajuda na abertura de um canal afetivo para o trabalho que se seguirá. Santos (2005) afirma que é importante que a experiência positiva seja detectada e registrada, antes da negativa, pois as frustrações podem bloquear as satisfações, Em geral, esse exercício de memória, em que emoções vêm à tona, proporciona um momento diferente e marcante na aula de Matemática.

Entretanto, na formação voltada aos professores, a proposta foi a de que, a partir das leituras sobre os direitos de aprendizagem e os eixos estruturantes de Matemática, eles 
refletissem sobre os seus conhecimentos e suas práticas nessa área, de modo que as experiências por eles descritas fossem, então, substituídas pelos conhecimentos que julgavam dominar. E os conhecimentos sobre os quais julgavam que deviam se aprofundar nos estudos, pois apresentavam deficiências, foram diagnosticados num processo de autorreflexão, a partir das leituras realizadas.

A atividade mostrou-se promissora, uma vez que, ao evocar suas memórias, os professores perceberam que os acontecimentos positivos estavam, muitas vezes, ligados a questões afetivas envolvendo o professor e que os aspectos negativos, normalmente, tinham a ver com a falta de compreensão do conteúdo, causando lacunas ainda presentes em seu conhecimento matemático, as quais deveriam ser preenchidas pelos estudos realizados na formação.

Já na segunda atividade, através da Linha do Numeramento, propunha-se aos cursistas que realizassem a retomada das experiências com os usos dos números, das operações, das medidas e de seus registros matemáticos, desde a $1^{\mathrm{a}}$ infância até a vida adulta, com discussão e trabalho em grupos, com registro em papel pardo e posterior apresentação coletiva.

Esta atividade permitiu o resgate das experiências pessoais que revelaram a importância e a presença constante da Matemática em nosso cotidiano, desde que nascemos, só se encerrando quando morremos, à semelhança das práticas de letramento (estudadas, em 2013, na formação). Os professores puderam perceber, com essa atividade, que não é somente na escola que estamos em interação com os usos da Matemática e que ela está presente em muitas situações cotidianas, mesmo que não a percebamos. A partir dessa reflexão, os professores ficaram sensibilizados sobre a importância de um trabalho com a Matemática nos anos iniciais, voltado às práticas de Alfabetização, num trabalho integrado com a alfabetização linguística e as práticas de letramento.

Os outros dois recursos citados, utilizados na formação, tinham o caráter permanente, sendo mobilizados, ao longo dos encontros, durante todo o período do curso: $o$ livro da vida e a caderneta de metacognição.

Segundo a descrição da coordenadora adjunta, professora Marta Nörnberg, o livro da vida foi uma atividade proposta tendo por referência o trabalho de Ruiz (2012), propondo o livro da vida como uma das técnicas operadas por Célestin Freinet, objetivando o registro da "livre expressão", relatando acontecimentos experimentados e vivenciados no cotidiano. Esse registro pode ser realizado de múltiplas maneiras, atendendo a diferentes propósitos, tanto dos professores quanto das crianças. Tem a função de comunicar, informar e socializar as novidades, conhecimentos e curiosidades. Pode ser estendido à família com o empréstimo do livro, compartilhando com a escola a importância de registrar as atividades do cotidiano.

No caso da formação, o livro da vida foi um registro coletivo, com as reflexões e indagações do grupo, diariamente realizado, por todos do grupo ou por um representante. 
Para mobilizar a reflexão, foi sugerido o início do registro a partir de uma questão que o próprio caderno de Formação Continuada propõe:

- Quais práticas formativas experimentadas favorecem ou privilegiam o desenvolvimento das habilidades importantes para a formação continuada, especialmente enquanto professores alfabetizadores?

Conforme a dinâmica de cada grupo, outras perguntas - que o formador considerasse pertinentes ou que o grupo tivesse a necessidade de registrar - eram agregadas. Para o último dia do curso, sugeria-se acrescentar outras perguntas, problematizando quais critérios eles adotavam para julgar positivamente uma ação formativa, quais conhecimentos que pudessem ser considerados importantes para a formação continuada foram estudados nessa etapa, entre outros.

Esse material ficava sob a responsabilidade da turma durante os encontros de formação, que podiam variar de três a cinco dias por mês. Muitos registros contribuíram para a autorreflexão do formador, permitindo-lhe repensar a sua prática entre uma formação e outra, aprofundando ou, simplesmente, retomando determinados temas, por indicação da turma em seus registros nesse livro.

Dentre as demandas surgidas referentes ao estudo dos conceitos matemáticos, foram recorrentes temas como o ensino do Sistema de Numeração Decimal, com sentido e significado para o aluno, a exploração de conceitos geométricos, com os quais as professoras declaravam ter grande dificuldade, pelo pouco contato que tiveram com o tema durante s sua formação e/ou escolaridade, além de temas emergentes na legislação, a exemplo do tratamento da informação estatística.

Sobre esses dois últimos temas, as professoras reconheciam que, apesar de estarem presentes na legislação, pelo menos, desde o lançamento dos PCNs, ainda não estavam efetivamente presentes em suas práticas, pois, novamente, não tinham sido abordados em sua formação inicial, revelando novamente a importância da formação continuada para a qualificação de suas práticas.

Por outro lado, também eram recorrentes os registros, n’o livro da vida, sobre as dificuldades com o uso de materiais manipulativos para o ensino de Matemática, pois, segundo as professoras, esses recursos não foram trabalhados na escola que frequentaram e, no curso de formação, a ênfase era sobre os estudos teóricos, sendo que esses recursos pedagógicos dificilmente eram abordados nas aulas regulares, restringindo o contato com eles nas oficinas ou outros espaços acadêmicos, que nem sempre contemplavam todas as estudantes.

Finalmente, outro recurso utilizado nas formações e que consideramos pertinente apresentar neste texto é a caderneta de metacognição. De acordo com o material produzido pela coordenadora, professora Marta Nörnberg, para uso nas formações, essa caderneta foi proposta a partir do trabalho com o texto proposto por Damiani, Gil e Protásio (2006), que 
apresentam uma experiência pedagógica de formação de professoras na qual a metacognição é um recurso auxiliar do processo formativo.

Cada formador recebeu, no início do curso, um caderno de 50 páginas, no qual deveria registrar, individualmente, suas percepções sobre a formação, num exercício metacognitivo, devendo refletir sobre os processos de aprender mobilizados na formação do PNAIC, produzindo um texto a partir das três questões propostas como um guia para a escrita na caderneta de metacognição (O que eu aprendi? Como eu aprendi? O que não entendi?). A intenção dessa atividade era que o professor - orientador de estudos explicitasse suas crenças, objetivos/metas e conhecimentos, percebendo que eles se afetam, mutuamente, na concretização dos processos de ensino e, sobretudo, percebendo que tal interação resulta em tomadas de decisão e ações - momento-a-momento - na sua atuação em sala de aula.

Para que a produção dos orientadores de estudos fosse além de um texto meramente descritivo que, em sua essência, não é considerado reflexivo, uma vez que apresenta apenas o registro de eventos ou de exemplos relatados na literatura, sem conter elementos que ofereçam razões ou justificativas para que ocorresse o que é relatado, os cursistas deveriam realizar um processo reflexivo sobre suas escritas, mobilizando, assim, o exercício metacognitivo pretendido com a atividade.

Foi possível perceber que, inicialmente, uma grande resistência dos professores em realizar essa atividade, e que, gradualmente, foram cedendo, ao compreenderem o seu significado e os objetivos. Puderam, então, realizar importantes registros sobre suas aprendizagens pessoais nesse processo formativo, contribuindo sobremaneira para uma real apropriação das temáticas estudadas.

\section{Conclusão}

Certamente, este texto não é conclusivo, nem se encerra em si mesmo: é para ser lido e compreendido dentro de um determinado contexto, com a complementaridade das fontes bibliográficas e demais referências usadas/citadas.

Entretanto, algumas questões devem ficar bem compreendidas pelo leitor. Devemos, por exemplo, considerar que, independentemente do recurso a ser utilizado para o ensino de Matemática nos anos iniciais, é fundamental que o professor reconheça e respeite os diferentes tempos dos alunos, pois os primeiros contatos formais com a Matemática poderão ser decisivos para um bom aproveitamento ao longo da escolaridade.

O desenvolvimento do raciocínio lógico matemático promove e amplia a prédisposição para outros aprendizados, dentre os quais pode-se destacar o desenvolvimento do processo de alfabetização, ou seja, a Matemática não atrasa ou "rouba” tempo de outras aprendizagens, ao contrário, ela cria condições para que essas aprendizagens se efetivem. 
Assim, cada vez mais, o professor precisa contemplar, em seus planejamentos dos anos iniciais, essa matéria do ensino, normalmente negligenciada nessa etapa da escolaridade.

Entretanto, não se deve pensar que ensinar Matemática pode se resumir ao uso do quadro e giz e ao desenvolvimento de algoritmos mecânicos, que não desenvolvem nenhuma habilidade dos alunos, além da repetição. Assim, o ensino de Matemática deve se desenvolver pela mobilização de atividades variadas, com a utilização de múltiplos recursos combinados, como a resolução de problemas, a literatura, os jogos, materiais concretos, brincadeiras, etc.

Através do PNAIC, um importante momento de formação continuada fez-se propício aos professores dos anos iniciais que, embora sem formação em Matemática, são professores que ensinam Matemática e, portanto, precisam de um aprofundamento, tanto teórico quanto metodológico, nesse campo que, normalmente, é trabalhado de maneira superficial nos cursos de Pedagogia.

Entre os elementos que pautaram as discussões sobre o ensino de Matemática nos anos iniciais, o pano de fundo para as discussões foi o conceito de Alfabetização Matemática, sempre na insistência de que essa matéria de ensino não se resume à contagem e às operações, mas contempla muitas outras áreas dessa ciência apresentada aos estudantes, por vezes, de forma fechada, pronta e acabada, sem que qualquer construção conceitual possa ser desenvolvida. Na perspectiva da Alfabetização Matemática, essa concepção de ensino é refutada e problematizada em favor de um ensino baseado na resolução de problemas e na busca da construção efetiva do conhecimento.

\section{Referências:}

ALVES, A. M. M. A Matemática Moderna no ensino primário gaúcho (1960-1978): uma análise das coleções de livros didáticos Estrada Iluminada e Nossa Terra Nossa Gente. (Tese de Doutorado). Pelotas, 2013.

BRASIL, Ministério da Educação. Parâmetros Curriculares Nacionais: Matemática Brasília: MEC/SEF, 1997.

BRASIL, Ministério da Educação, Conselho Nacional de Educação. Câmara de Educação Básica. Resolução $N^{o} 7$, de 14 de dezembro de 2010. Diário Oficial da União, Brasília, 15 de dezembro de 2010, Seção 1, p. 34.

BRASIL, Ministério da Educação, Secretaria de Educação Básica. Elementos conceituais e metodológicos para definição dos direitos de aprendizagem e desenvolvimento do ciclo de alfabetização $\left(1^{\circ}, 2^{\circ}\right.$ e $3^{\circ}$ anos do Ensino Fundamental). Brasília, 2012. Disponível em: portal.mec.gov.br

BRASIL. Pacto Nacional pela Alfabetização na Idade Certa: Apresentação. Ministério da Educação, Secretaria de Educação Básica, Diretoria de Apoio à Gestão Educacional. Brasília: MEC, SEB, 2014.

CANÁRIO, R. Centros de formação das associações de escolas: que futuro? In: AMIGUINHO, A.; CANÁRIO, R. Escolas e mudança: o papel dos centros de formação. Lisboa: EDUCA, 1994.

CURI, E. A Matemática e os professores dos anos iniciais. São Paulo: Kusa, 2005. 
DAMIANI, M.; GIL, R.; PROTÁSIO, M. A metacognição como auxiliar no processo de formação de professoras: uma experiência pedagógica. In: UNIrevista - Vol. 1, n 2, pp. 0314, abril. 2006.

DANYLUK, O. Alfabetização Matemática: as primeiras manifestações da escrita infantil. Porto Alegre: Sulina; Passo Fundo: Ediupf, 1998.

LIMA, L. Piaget para principiantes. São Paulo: SUMMUS Editora, 1980.

MACHADO, N. Matemática e língua materna. São Paulo: Cortez, 1990.

MORETTI, V.; SOUZA, N. Educação Matemática nos anos iniciais do ensino fundamental: princípios e práticas pedagógicas. São Paulo: Cortez, 2015.

NACARATO, A.; MENGALI, B.; PASSOS, C. A Matemática nos Anos Iniciais do Ensino Fundamental: tecendo fios do ensinar e do aprender. Belo Horizonte: Autêntica Editora, 2014.

RAMOS, L. Conversas sobre números, ações e operações: uma proposta criativa para o ensino da Matemática nos primeiros anos. São Paulo: Ática, 2009.

RUIZ, S. Livro da Vida: uma prática de letramento escolar na educação infantil. In: Estudos em Educação e Linguagem, v. 2, n. 1, pp. 1-16, 2012.

SANTOS, S. Explorações da Linguagem escrita nas aulas de Matemática. In: LOPES, C.; NACARATO, A. (orgs.). Escritas e Leituras na Educação Matemática. Belo Horizonte: Autêntica, 2005.

SMOLE, K. Matemática e Literatura Infantil. (4a. ed.) Belo Horizonte: Lê, 1999.

SOARES, M. Letramento e alfabetização: as muitas facetas. In: Revista Brasileira de Educação. Rio de Janeiro, nº 25, pp. 5-17, 2004.

SOARES, M. Letramento: um tema em três gêneros. 2ed. Belo Horizonte: Autêntica, 2006.

TOLEDO, M. Numeramento e escolarização: o papel da escola no enfrentamento das demandas Matemáticas cotidianas. In: FONSECA, Maria da Conceição. Letramento no Brasil: Habilidades Matemáticas. São Paulo: Global: Ação Educativa Assessoria, pesquisa e Informação: Instituto Paulo Montenegro, 2004.

PIAGET, J. O Estruturalismo. 3 ed. São Paulo - Rio de Janeiro: Difel, 1979.

PIAGET, J.; INHELDER, B. Gênese das estruturas lógicas elementares. 2 ed. Rio de Janeiro: Zahar Editores, 1975.

WARSCHAUER, C. Rodas em Rede. Oportunidades formativas na escola e fora dela. São Paulo: Paz e Terra, 2003. 